\title{
Neuronal stem cells in the central nervous system and in human diseases
}

\author{
Qian Wu ${ }^{\bowtie}$, Xiaoqun Wang ${ }^{\bowtie}$ \\ State Key Laboratory of Brain and Cognitive Science, Institute of Biophysics, Chinese Academy of Sciences, \\ Beijing 100101, China \\ $\triangle$ Correspondence: qianwu@moon.ibp.ac.cn (Q.Wu), xiaoqunwang@ibp.ac.cn (X. Wang) \\ Received April 5, 2012 Accepted April 9, 2012
}

\begin{abstract}
The process of cortical expansion in the central nervous system is a key step of mammalian brain development to ensure its physiological function. Radial glial (RG) cells are a glial cell type contributing to this progress as intermediate neural progenitor cells responsible for an increase in the number of cortical neurons. In this review, we discuss the current understanding of RG cells during neurogenesis and provide further information on the mechanisms of neurodevelopmental diseases and stem cell-related brain tumorigenesis. Knowledge of neuronal stem cell and relative diseases will bridge benchmark research through translational studies to clinical therapeutic treatments of these diseases.
\end{abstract}

KEYWORDS radial glial cell, neuronal stem cell, tumorigenesis, glioma

\section{INTRODUCTION}

One of the major features of mammalian brain evolution is cortical expansion. The volume of the human brain is larger than any other primate and is disproportionate with body size. Understanding how the human cerebral cortex develops to its complicated state and identification of neural stem cells and progenitor cells, as well as the lineages they produce, are keys to ascertaining how the enormous diversity of cell types is produced in the brain. This information will provide further understanding of the mechanisms of neurodevelopmental diseases and stem cell-related tumorigenesis. In the past century, neurons were thought to be derived from neuroblasts where radial glial $(R G)$ cells were the precursor cells of as- trocytes. However, in the past 20 years, studies have suggested that RG cells are only responsible for a small population of astrocytes. More importantly, RG cells serve as neural stem cells/neural precursor cells for neuron genesis during development.

\section{RADIAL GLIAL CELLS}

Over the last two decades, a great amount of information on brain development and disease has been produced. In this review, we summarize the progress on neuronal stem cell and brain tumor studies, which will hopefully help the readers obtain the whole picture of brain developmental research in the past two decades. Alvarez-Buylla et al. first reported the possible neural progenitor based on the finding of vimentin-positive radial cells in the songbird ventricular zone (VZ) (Alvarez-Buylla et al., 1990). Lineage analysis using retroviruses in chick and rodent telencephalons identified clones containing single RG cells and multiple neurons, suggesting that radial glia and neurons are clonally related cells (Gray and Sanes, 1992; Halliday and Cepko, 1992). Subsequently, with both in vivo and in vitro methods, RG cells have been proven to be neural precursors. RG cells have been traditionally characterized by their characteristic bipolar morphology and by their contact with both ventricular and pial surfaces. Whole-cell patch-clamp recordings with single-cell dye labeling have revealed the morphology and measured the membrane properties of randomly chosen cells in contact with the ventricular surface, suggesting that cells with the characteristic morphological features of RG cells have the physiological features of precursor cells (LoTurco et al., 1991; Noctor et al., 2002). Similarly, the application of Dil or fluorescent microbeads to the pial surface of developing neocortex labels mitotically active VZ cells with distinct RG morphology (Malatesta et al., 2000; Miyata et al., 2001), and has 
demonstrated that these cells constitute more than $90 \%$ of mitotically active cells in the VZ (Noctor et al., 2002, 2004).

Through lineage studies using retroviruses in chick and rodent telencephalons, radial glia and neurons are suggested to be lineally related (Gray and Sanes, 1992; Halliday and Cepko, 1992), whereas solid studies have confirmed that rodent RG cells act as neural precursor cells (Malatesta et al., 2000; Miyata et al., 2001; Noctor et al., 2001, 2004; Tamamaki et al., 2001). The vast majority of dividing cells in the neocortical VZ, either in the S-phase or in the M-phase, express RG markers. Together with the observation that RG cells are the only mitotic cells in radial clones consisting of neurons and radial glia, this finding confirms that radial glia generates neurons in vivo. Furthermore, this cell type may represent the predominant neural precursor within the VZ of the developing neocortex (Malatesta et al., 2000; Miyata et al., 2001; Noctor et al., 2001, 2004; Tamamaki et al., 2001).

\section{RG cell division in neocortical development}

Mitotic figures have been observed in subventricular zone (SVZ) for over a century. However, the types of cells undergoing mitosis are still unclear. Recent studies indicate that throughout most of neurogenesis, other than an active role in VZ, RG cells also divide to populate the embryonic SVZ (Haubensak et al., 2004; Miyata et al., 2004; Noctor et al., 2004, 2007b). RG cells usually undergo asymmetric cell division to yield a new RG cell and a neuron or an intermediate neural progenitor cell (IPC) (Fig. 1) (Haubensak et al., 2004; Noctor et al., 2004, 2007b). IPC then divides symmetrically to generate two neurons or two additional IPCs (Wu and Cepko, 1993; Haubensak et al., 2004; Miyata et al., 2004; Noctor et al., 2004, 2007a). Therefore, embryonic SVZ is increasingly considered as a major site of neurogenesis, whereas symmetric division is recognized to transit amplifying division (Miyata et al., 2001, 2004; Tarabykin et al., 2001; Smart et al., 2002; Nieto et al., 2004; Noctor et al., 2004, 2007b; Zimmer et al., 2004; Martínez-Cerdeño et al., 2006).

During mitosis, several studies have illustrated that RG cells remain in place without retraction from the pial surface throughout the whole cell cycle (Miyata et al., 2001; Noctor et al., 2001, 2002; Tamamaki et al., 2001; Weissman et al., 2004). Within the radial fiber of RG cells, the cytoplasm climbs toward the cell body with varicosities showing at intervals along the attenuated fiber (Miyata et al., 2001; Noctor et al., 2001, 2002; Tamamaki et al., 2001; Weissman et al., 2004). In addition to generating neurons, RG cells supply the fibers for neuronal migration (Rakic, 1978). Both in vivo and in vitro evidence has demonstrated that daughter neurons migrate along the pial fibers of mother RG cells out of the VZ, and many of these cells maintain an association with the parental fiber as they migrate to the cortical plate. The number of genes has been discovered to be related with neuronal migration (Kriegstein and Götz, 2003; Cooper, 2008), includ-

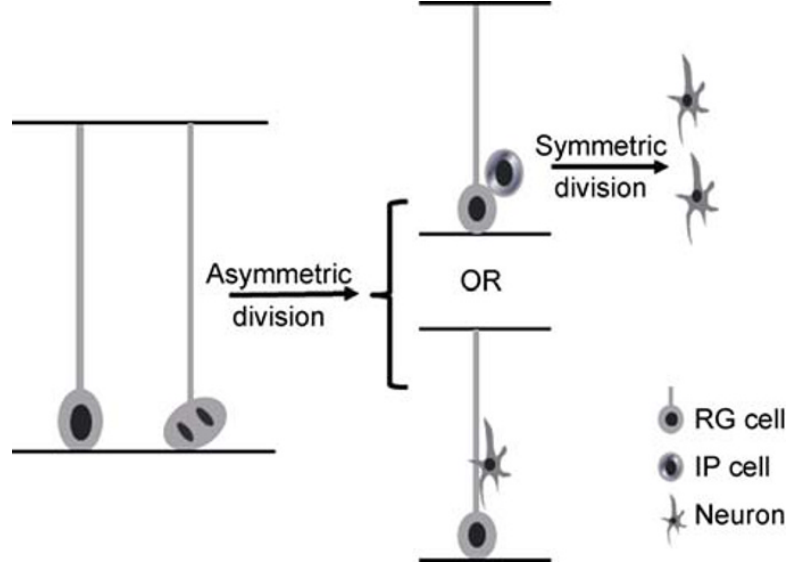

Figure 1. Radial glial (RG) cell division in neurogenesis. During neurogenesis, RG cells divide asymmetrically in two ways: producing an RG cell and a neuron or generating an RG cell and an intermediate neural progenitor cell (IPC), which undergo symmetrical divisions to produce two neurons, thereby increasing cell population in embryonic subventricular zone.

ing CDK5 and its subunits, microtubule-associated proteins, and centrosome proteins, such as Lis1 (Niethammer et al., 2000). Alternatively, different classes of cortical neurons may use different mechanisms to migrate to the cortical plate. Most, if not all, cortical neurons in the SVZ or intermediate zone have been recently shown to pause during their migration and exhibit a multipolar morphology. During the multipolar phase, cortical neurons do not contact either the pial or the ventricular surface. After a day or more, the cortical neurons assume a bipolar morphology and resume radial migration toward the cortical plate (Noctor et al., 2004). Once neurons migrate into the cortical plate, they utilize two modes of neuronal migration: soma translocation and locomotion. Locomotion or glia-dependent locomotion is a salutatory behavior where the cell extends a leading process, moves its nucleus forward, retracts the rear, and then repeats the cycle. Attachments to the radial glia involve the gap junction (Elias et al., 2007). Centrosome and myosin are important for locomotion (Umeshima et al., 2007). Somal translocation is much faster compared with locomotion. The leading process, anchoring in the pial surface during the process of somal translocation, shortens as the cell soma moves rapidly upward (Umeshima et al., 2007).

Notch signaling has been demonstrated as a critical regulator of RG cells and IPC proliferation. IPC and migrating neurons activate Notch in RG cells via expressing mind bomb-1 (mib1) (Yoon et al., 2008), suggesting that IPC and daughter neurons may maintain RG proliferation ability through Notch signal activation by contacting RG radial fibers during migration. Interestingly, some studies have indicated that the proliferation of RG cells and IPC may be regulated by different Notch signal transductions. Proliferating signals in RG cells, but not in IPC, are activated by the canonical Notch effector C-promoter binding factor 1 (CBF1) (Mizutani et al., 2007). 
Prior to the formation of a distinct SVZ, IPCs are also observed within the VZ or in the predominant site of neurogenesis, mixed with RG cells (Noctor et al., 2007b). This observation has answered the question regarding the kind of non-RG cells that undergo mitosis in the developing embryonic VZ (Levitt and Rakic, 1980; Gal et al., 2006). Unlike RG cells which undergo asymmetrical division during the peak of neurogenesis, IPCs divide symmetrically to generate two neurons or to produce two daughter IPCs (Wu and Cepko, 1993; Haubensak et al., 2004; Miyata et al., 2004; Noctor et al., 2004, 2007a). In rodents, the majority of symmetric divisions of IPC produce neurons, whereas only approximately $10 \%$ of the divisions end with new IPCs (Haubensak et al., 2004; Noctor et al., 2004). In other species, IPC may exist in the outer SVZ of the fetal primate brains where large numbers of mitotic cells contribute to the cortical expansion in primates (Kriegstein et al., 2006). Hence, the evidence above indicates that RG cells serving as neuronal stem/precursor cells play a critical role in the cortical expansion during brain development in mammals.

\section{Neuronal lineage of RG cells}

The cerebral cortex is a six-layered structure consisting of two broad cases of neurons: excitatory neurons and inhibitory interneurons. Excitatory neurons are neocortical projection neurons that send axons to other brain regions and communicate via the excitatory neurotransmitter glutamate. Most inhibitory neurons are organized into local circuits and use $\gamma$-aminobutyric acid (GABA) as a neurotransmitter. Previously, both pyramidal and inhibitory neurons have been believed to originate from the same progenitor (Price and Thurlow, 1988). However, more studies in retroviral infections (Luskin et al., 1993) and immunohistochemistry (Mione et al., 1994) have indicated only one cell type in the same clones and that pyramidal neurons and interneurons emerge from separate precursors. GABAerg interneurons are generated in the ganglionic eminence, particularly the medial ganglionic eminence, and tangentially migrate into the developing neocortex (Anderson et al., 1997; Tamamaki et al., 2001). In summary, RG cells generate glutamatergic principal neurons in the neocortical VZ, whereas a majority of GABAergic interneurons are generated in the ganglionic eminence and tangentially migrate into the cortex.

\section{RG CELLS AND NEURODEVELOPMENTAL DISEASES}

\section{Autosomal recessive primary microcephaly (MCPH)}

$\mathrm{MCPH}$ is a neurodevelopmental disease characterized by a decrease in brain volume with normal brain architecture. Patients experience neurological and psychiatric symptoms, including seizures, mental retardation, delayed motor and speech function, hyperactivity, attention deficit, and balance and coordination difficulties (Kaindl et al., 2010). Recent studies have demonstrated that mutations of centrosomal proteins are related to $\mathrm{MCPH}$, such as microcephalin (MCPH1) (Jackson et al., 1998, 2002) centromere-associated protein J (Cenpj) (Bond et al., 2005), abnormal spindle-like microcephaly-associated protein (ASPM) (Pattison et al., 2000), cyclin-dependent kinase 5 regulatory-associated protein 2 (Cdk5rap2) (Bond et al., 2005), and the pericentriolar gene STIL (Kumar et al., 2009), leading to defects in neurogenesis. In the mouse brain, Cdk5rap2 is highly expressed in the neural progenitor pool, which accounts for the depletion of RG cells and the increase of cell cycle exit, resulting in premature neuronal differentiation (Megraw et al., 2011). Cdk5rap2 has recently been shown to stimulate microtubule nucleation (Choi et al., 2010) and regulate centriole replication (Barrera et al., 2010) via a tight link to pericentrin (Buchman et al., 2010). In mouse models, ASPM has been shown to be involved in maintaining symmetric divisions of RG cells and in completing cytokinesis (Kouprina et al., 2005; Higgins et al., 2010). Mutation in Nde1, a centrosomal gene, is the cause of a disease called microlissencephaly, which is characterized by extreme microcephaly and grossly simplified cortical gyral structure (Alkuraya et al., 2011). In mice with Nde1 knocking out, RG cells exhibit dramatic defects in mitotic progression, orientation, and chromosome localization, as well as neuronal cell fate determination. Detections of loss of human Nde1 are used as risk factors for microcephaly, mental retardation, and epilepsy (Ghannad, 2011).

\section{Lissencephaly}

Lissencephaly, another neurodevelopmental disease characterized by lack of development of brain gyri and sulci in embryo gestation, causes severe neurological impairment in newborn infants and death within several months of birth (Bauman, 1987; Dobyns, 1987). One of the known lissencephaly-related genes is Lis1, whose mutation causes lissencephaly in the human brain. In rodents, knockdown of Lis1 results in the arrest of centrosomal and nuclear movements during neuronal migration and the disruption of basal-to-apical interkinetic nuclear migration (INM). Furthermore, tubulin-related defects seem to be associated to neurodevelopmental disorder pathogenesis. Mutations in alpha and beta tubulins, required for microtubule polymerization for motor protein binding, can cause severe lissencephaly and microcephaly in human patients (Tischfield et al., 2011).

\section{RG CELLS AND GLIOMAS}

Glioma, the most common brain tumor, is one of the most lethal human cancers in adults. Some of the cases are thought to have potentially originated from the SVZ in the brain, where neural stem cells and neural progenitor cells are abundant (Sutton et al., 1992; Tohyama et al., 1992; Alvarez-Buylla and Garcia-Verdugo, 2002). In animal models, the 
regions of the brain with proliferating cells, such as stem cell or progenitor cell populations, are more sensitive to oncogenic inducers than the areas with inactive proliferating cells (Hopewell, 1975; Vick et al., 1977). By contrast, mature mouse astrocytes are less susceptible to be transformed in vivo unless they are undifferentiated via platelet-derived growth factor (PDGF) expression or Ink4a-Arf down-regulation (Bachoo et al., 2002; Uhrbom et al., 2002). This finding indicates that undifferentiated stem cells and progenitor cells in the central nervous system (CNS) have high potential for malignant transformation. Current studies have shown evidence that adult rat stem cells from SVZ are transformed into tumorigenic cell lines after expansion in vitro (Siebzehnrubl et al., 2009). As proliferating neuronal precursor cells, RG cells can thus be a source of cancer stem cells in the brain.

\section{Molecular markers of glioma stem cells}

Glioma stem cells (GSC) are characterized by self-renewal, multipotent, and tumorigenic properties in the glioma. GSC have been shown to express Nestin, a classic neural stem cell marker and the surface marker cluster of differentiation (CD) 133 (also known as prominin 1), which are nowadays used as clinical prognosis molecules for glioma (Lendahl et al., 1990; Ignatova et al., 2002; Singh et al., 2003; Singh et al., 2004; Yuan et al., 2004; Zhang et al., 2008). However, recent results suggest that $\mathrm{CD} 133$ expression may not be a reliable marker for the tumorigenic ability of stem cells in the brain. In the conditional knockout of the CD133 animal model, glioma can be formed from the cell population without CD133 expression (Nishide et al., 2009). In addition, both CD133-positive and CD133-negative human glioma-derived stem cell clones exhibit tumor formation ability (Chen et al., 2010). Some embryonic stem cell markers associated with glioma identification and aggressiveness, such as Oct4, Nanog, and Sox2, have been used for the guidance of glioma therapeutic selection (Ben-Porath et al., 2008; Holmberg et al., 2011; Shats et al., 2011). Interestingly, Nanog expression correlates with the ability of GSC formation and the malignancy of glioma clinical samples (Zbinden et al., 2010; Niu et al., 2011).

\section{Therapeutic approaches to glioma}

Due to the blood-brain barrier, the drug delivery efficacy of current therapies for glioma is poor. One method for improving the approaches and efficacy of brain tumor treatments is the study of the property and specificity of GSC. In the following paragraphs, we discuss current knowledge of GSC and related therapies.

\section{DNA repair pathways and glioma therapies}

Classical and standard treatments of glioma nowadays are surgical removal, ionizing radiation (IR), and temozolomide (TMZ). However, GSC are resistant to IR and TMZ treatments due to the dysregulation in DNA repair pathways. Among CD133-positive GSC, DNA repair is more efficient and leads to an increase of CD133-positive cells in the tumor after IR treatment (Bao et al., 2006a; Tamura et al., 2010). DNA checkpoint kinases, Chk1 and Chk2, which play essential roles in DNA repair, are highly activated during IR in CD133-positive GSC. The inhibition of Chk1 and Chk2 significantly increases GSC radio-sensitivity (Bao et al., 2006a). Further studies have illustrated that the knockdown of some other DNA repair-related genes, such as L1CAM, NBS-1, and Bim1, reduces GSC radioresistance (Facchino et al., 2010; Cheng et al., 2011), suggesting that hyper-active DNA repair pathways make radiotherapy less effective in the clinical treatment of gliomas.

Other than radioresistance induction, the DNA repair pathway also plays a role in chemoresistance in glioma therapies. The methylation status of O6-methylguanine-DNAmethyltransferase (MGMT), a DNA repair enzyme, is highly correlated with the efficiency of TMZ treatment in glioma patients whose methylated (epigenetically silenced) form of this gene is more sensitive to TMZ than the ones with active MGMT (Hegi et al., 2005; Liu et al., 2006).

\section{Growth factors as glioma treatment targets}

Decades of research demonstrate that the epidermal growth factor (EGF) signaling pathway plays an important role in neural stem cell regulation and tumorigenesis. The activation of EGFR triggers classic PI3K-Akt or Ras-MAPK signals, thus regulating cell proliferation and migration (Wells et al., 2002). EGFR activation promotes cell growth of astrocyte precursors and neural stem cells (Reynolds et al., 1992; Seidman et al., 1997; Kornblum et al., 1998). In high-grade astrocytomas, the most common type of glioma, approximately $50 \%$ of cases exhibit EGFR amplification, and this activation appears critical in the transformation process (Maher et al., 2001; Wechsler-Reya and Scott, 2001). However, in animal models, only EGFR mutation is not sufficient for tumor generation. Genetic mouse models require a minimum of three lesions, a mutant EGFR, and deletions of both p16 and PTEN to allow gliomagenic transformation (Zhu et al., 2009). The inhibition of EGFR signals by EGFR inhibitors erlotinib and gefitinib (two known anti-cancer drugs) blocks GSC proliferation and induces apoptosis. However, the sensitivity of GSC to these inhibitors is correlated with PTEN expression and Akt inhibition (Soeda et al., 2008; Griffero et al., 2009). Further studies on Akt signaling pathways, a downstream effector of EGFR, have suggested that CD133-positive GSC most likely activate Akt signals which are sensitive to phosphatidylinositol ether lipid analog (AKTIII). This molecule suppresses GSC proliferation and induces apoptosis, as well as reduces cell motility and invasiveness by inhibiting Akt signaling pathways (Eyler 
et al., 2008). Another Akt inhibitor, perifosine, is undergoing clinical trials of glioma treatments.

Angiogenesis is a key process for tumors to form new blood vessels during tumorigenesis. Co-implantation of GSC along with endothelial cells accelerates the initiation and growth of brain tumors in vivo (Calabrese et al., 2007), suggesting that angiogenesis is critical for glioma development. High expression of vascular endothelial growth factor (VEGF) is positively associated with grades of astrocytoma (Plate et al., 1992; Ferrara, 2004; Mizukami et al., 2007). In addition, Bao et al. showed that tumors originating from CD133-positive GSC are more vascular via the activation of VEGF signals (Bao et al., 2006b). Bevacizumab, an inhibitor of VEGF, has been tested in glioma treatment trials. Early laboratory data have indicated that bevacizumab reduces tumor size and decreases the number of CD133-positive GSC by affecting endothelial cells and depleting tumor vasculature (Bao et al., 2006b; Calabrese et al., 2007). Other than VEGF, PDGF is another essential regulating factor in glioma tumorigenesis. PDGF signals block the differentiation of neural stem cells and neural progenitor cells, thus inducing low-grade gliomas in vivo (Uhrbom et al., 1998; Dai et al., 2001). More evidence of retrovirally transfecting brain stem astrocytes with PDGF resulting in invasive gliomas suggests that PDGF is a key regulator in brain tumorigenesis (Assanah et al., 2006; Masui et al., 2010). Vatalanib, a tyrosine kinase inhibitor targeting VEGFR, PDGFR, and c-Kit, has been studied in phase $\mathrm{I} / \mathrm{II}$ clinical trials in recurrent glioma patients and in combination with other anti-cancer drugs. However, the efficacy is limited in these studies. More recently, vatalanib in combination with the PDGFR inhibitors, imatinib and hydroxyurea, has exhibited a better response rate in glioma patients (Reardon et al., 2009), indicating that anti-angiogenesis is a promising target for glioma therapies.

\section{Notch signaling pathways and potential therapeutic approaches}

As a conservative neuronal developmental signaling pathway, Notch plays a critical role in neural stem cell maintenance (Corbin et al., 2008). With the theory that tumors originate from stem cells, the Notch signaling pathway has been recently studied in the aspect of its relevance in glioma formation. Down-regulation of Notch-1 or blocking signals by inhibition of ligand binding in glioma cells results in reduced cell proliferation and increased cell death in vitro, as well as prolonged survival time of mice in vivo (Purow et al., 2005). In addition, Notch inhibition leads to a decrease of CD133positive GSC population and an increase in radiosensitivity in vivo (Fan et al., 2010; Lin et al., 2010). Other than its role in GSC, Notch is also a key regulator of tumor angiogenesis. The delta-like ligand (DII) 4, expressed in endothelial cells, is critical for vascular development (Benedito and Duarte, 2005). Using the neutralizing antibodies of DII4 in glioma leads to an increase of the dysfunctional vascular system (NogueraTroise et al., 2006; Ridgway et al., 2006), resulting in poor tumor perfusion, poor oxygenation, and reduced tumor growth. Due to the essential role of Notch signaling in glioma progression, gamma-secretase inhibitors (GSI), which block Notch activation by transcriptional regulation, can be considered as good candidates for glioma therapeutic drugs (Miele et al., 2006; Gordon et al., 2008; Kovall, 2008).

\section{Other therapeutic concerns and unconventional potential therapy methods in glioma}

Normal neural stem cells and GSC share similar cell markers and physiological properties, so traditional treatments, such as radiotherapy and chemotherapy, damage normal NSC while killing GSC. Therefore, investigating the different characteristics of these two populations is key to opening an avenue to explore more effective therapies for glioma patients. Array-based genome, transcriptome, or proteome can be powerful tools for the study and comparison of these different stem cell types.

Another way to specifically target tumor/GSC other than normal NSC is utilizing delivery vehicles to transport therapeutic agents to the designated area. Neural stem cells are known to be able to migrate to the injury and tumor mass. Studies have shown that exogenous murine embryonic neural stem cells or endogenous neural stem cells have capabilities to move toward xenografted tumor in vivo in murine models (Glass et al., 2005; Mapara et al., 2007). Hence, this homing ability of NSC may make these cells available as shuttles to transport therapeutic agents, such as cytokines, peptides, and so on. Due to the inaccessibility of autologous neural stem cells in practice, other autologous stem cells, such as mesenchymal stem cells (MSC) or iPSC, can also be considered as sources. These cells are easy to be obtained from many tissues and can be reprogrammed and expanded efficiently in vitro. However, the caveat for this methodology is that stem cells can be tumorigenic, and this transformation can happen spontaneously, which may cause a worse disease condition (Birnbaum et al., 2007).

\section{SUMMARY}

RG cells can be found in the earliest stages of CNS development and play an important role in cortical expansion. RG cells have a unique morphology with a periventricular cell body that extends to the pial surface. RG cells recently have been identified as neural precursor cells which divide asymmetrically to self-renew and produce IPC or a neuron during the period of peak neurogenesis. Unlike RG cells, IPC undergo symmetrical divisions to produce two neurons or two additional IPCs to populate the embryonic SVZ. In neurogenesis, RG cells typically generate glutamatergic principal neurons in the neocortical VZ, whereas a majority of 
GABAergic interneurons are generated in the ganglionic eminence and tangentially migrate into the cortex. After cortical neurogenesis is complete in the VZ, RG cells transform into astrocytes. This biological understanding of RG cell behavior benefits pathogenic studies of RG cell-related diseases. We have discussed neurodevelopmental disorders and brain tumors in this review. Lissencephaly and microcephaly are associated with RG cell division defects caused by centrosomal or microtubule protein dysregulation. In glioma studies, the microenvironment of GSC plays a role in glioma tumorigenesis. DNA repair mechanisms, growth factors (EGF, VEGF, and PDGF), and Notch signaling pathways are all involved in regulating neural stem cells and neural progenitor cell proliferation and differentiation, leading to glioma pathogenesis. Future studies on understanding the regulation of $R G$ cell division, differentiation, and migration in CNS development will not only answer basic biological questions, but also provide information on the mechanisms of related disorders. With these findings, neural stem/progenitor cell can be utilized as a new source for disease therapies.

\section{ACKNOWLEDGEMENTS}

This work was supported by the National Basic Research Program of China (Grant No. 2012CB966800) and the 1000 Young Talents Program.

\section{ABBREVIATIONS}

ASPM, abnormal spindle-like microcephaly-associated protein; CBF1, C-promoter binding factor 1; $C D$, cluster of differentiation; CNS, central nervous system; EGF, epidermal growth factor; GABA, $\gamma$-aminobutyric acid; GSC, glioma stem cells; GSI, gamma-secretase inhibitors; INM, interkinetic nuclear migration; IPC, intermediate neural progenitor cell; IR, ionizing radiation; $\mathrm{MCPH}$, autosomal recessive primary microcephaly; MGMT, O6-methylguanine-DNA- methyltransferase; MSC, mesenchymal stem cells; PDGF, platelet-derived growth factor; RG, radial glial; SVZ, subventricular zone; VZ, ventricular zone

\section{REFERENCES}

Alkuraya, F.S., Cai, X., Emery, C., Mochida, G.H., Al-Dosari, M.S., Felie, J.M., Hill, R.S., Barry, B.J., Partlow, J.N., Gascon, G.G., et al. (2011). Human mutations in NDE1 cause extreme microcephaly with lissencephaly [corrected]. Am J Hum Genet 88, 536-547.

Alvarez-Buylla, A., and Garcia-Verdugo, J.M. (2002). Neurogenesis in adult subventricular zone. J Neurosci 22, 629-634.

Alvarez-Buylla, A., Kirn, J.R., and Nottebohm, F. (1990). Birth of projection neurons in adult avian brain may be related to perceptual or motor learning. Science 249, 1444-1446.

Anderson, S.A., Eisenstat, D.D., Shi, L., and Rubenstein, J.L. (1997). Interneuron migration from basal forebrain to neocortex: dependence on Dlx genes. Science 278, 474-476.
Assanah, M., Lochhead, R., Ogden, A., Bruce, J., Goldman, J., and Canoll, P. (2006). Glial progenitors in adult white matter are driven to form malignant gliomas by platelet-derived growth factor-expressing retroviruses. J Neurosci 26, 6781-6790.

Bachoo, R.M., Maher, E.A., Ligon, K.L., Sharpless, N.E., Chan, S.S., You, M.J., Tang, Y., DeFrances, J., Stover, E., Weissleder, R., et al. (2002). Epidermal growth factor receptor and Ink4a/Arf: convergent mechanisms governing terminal differentiation and transformation along the neural stem cell to astrocyte axis. Cancer Cell 1, 269-277.

Bao, S., Wu, Q., McLendon, R.E., Hao, Y., Shi, Q., Hjelmeland, A.B., Dewhirst, M.W., Bigner, D.D., and Rich, J.N. (2006a). Glioma stem cells promote radioresistance by preferential activation of the DNA damage response. Nature 444, 756-760.

Bao, S., Wu, Q., Sathornsumetee, S., Hao, Y., Li, Z., Hjelmeland, A.B., Shi, Q., McLendon, R.E., Bigner, D.D., and Rich, J.N. (2006b). Stem cell-like glioma cells promote tumor angiogenesis through vascular endothelial growth factor. Cancer Res 66, 7843-7848.

Barrera, J.A., Kao, L.R., Hammer, R.E., Seemann, J., Fuchs, J.L., and Megraw, T.L. (2010). CDK5RAP2 regulates centriole engagement and cohesion in mice. Dev Cell 18, 913-926.

Bauman, M.L. (1987). Neuroembryology-clinical aspects. Semin Perinatol 11, 74-84.

Ben-Porath, I., Thomson, M.W., Carey, V.J., Ge, R., Bell, G.W., Regev, A., and Weinberg, R.A. (2008). An embryonic stem cell-like gene expression signature in poorly differentiated aggressive human tumors. Nat Genet 40, 499-507.

Benedito, R., and Duarte, A. (2005). Expression of DII4 during mouse embryogenesis suggests multiple developmental roles. Gene Expr Patterns 5, 750-755.

Birnbaum, T., Roider, J., Schankin, C.J., Padovan, C.S., Schichor, C., Goldbrunner, R., and Straube, A. (2007). Malignant gliomas actively recruit bone marrow stromal cells by secreting angiogenic cytokines. J Neurooncol 83, 241-247.

Bond, J., Roberts, E., Springell, K., Lizarraga, S.B., Scott, S., Higgins, J., Hampshire, D.J., Morrison, E.E., Leal, G.F., Silva, E.O., et al. (2005). A centrosomal mechanism involving CDK5RAP2 and CENPJ controls brain size. Nat Genet 37, 353-355.

Buchman, J.J., Tseng, H.C., Zhou, Y., Frank, C.L., Xie, Z., and Tsai, L.H. (2010). Cdk5rap2 interacts with pericentrin to maintain the neural progenitor pool in the developing neocortex. Neuron 66, 386-402.

Calabrese, C., Poppleton, H., Kocak, M., Hogg, T.L., Fuller, C., Hamner, B., Oh, E.Y., Gaber, M.W., Finklestein, D., Allen, M., et al. (2007). A perivascular niche for brain tumor stem cells. Cancer Cell 11, 69-82.

Chen, R., Nishimura, M.C., Bumbaca, S.M., Kharbanda, S., Forrest, W.F., Kasman, I.M., Greve, J.M., Soriano, R.H., Gilmour, L.L., Rivers, C.S., et al. (2010). A hierarchy of self-renewing tumor-initiating cell types in glioblastoma. Cancer Cell 17, 362-375.

Cheng, L., Wu, Q., Huang, Z., Guryanova, O.A., Huang, Q., Shou, W., Rich, J.N., and Bao, S. (2011). L1CAM regulates DNA damage checkpoint response of glioblastoma stem cells through NBS1. EMBO J 30, 800-813.

Choi, Y.K., Liu, P., Sze, S.K., Dai, C., and Qi, R.Z. (2010). CDK5RAP2 stimulates microtubule nucleation by the gammatubulin ring complex. J Cell Biol 191, 1089-1095. 
Cooper, J.A. (2008). A mechanism for inside-out lamination in the neocortex. Trends Neurosci 31, 113-119.

Corbin, J.G., Gaiano, N., Juliano, S.L., Poluch, S., Stancik, E., and Haydar, T.F. (2008). Regulation of neural progenitor cell development in the nervous system. J Neurochem 106, 2272-2287.

Dai, C., Celestino, J.C., Okada, Y., Louis, D.N., Fuller, G.N., and Holland, E.C. (2001). PDGF autocrine stimulation dedifferentiates cultured astrocytes and induces oligodendrogliomas and oligoastrocytomas from neural progenitors and astrocytes in vivo. Genes Dev 15, 1913-1925.

Dobyns, W.B. (1987). Developmental aspects of lissencephaly and the lissencephaly syndromes. Birth Defects Orig Artic Ser 23, 225-241.

Elias, L.A.B., Wang, D.D., and Kriegstein, A.R. (2007). Gap junction adhesion is necessary for radial migration in the neocortex. Nature 448, 901-907.

Eyler, C.E., Foo, W.C., LaFiura, K.M., McLendon, R.E., Hjelmeland, A.B., and Rich, J.N. (2008). Brain cancer stem cells display preferential sensitivity to Akt inhibition. Stem Cells 26, 3027-3036.

Facchino, S., Abdouh, M., Chatoo, W., and Bernier, G. (2010). BMI1 confers radioresistance to normal and cancerous neural stem cells through recruitment of the DNA damage response machinery. J Neurosci 30, 10096-10111.

Fan, X., Khaki, L., Zhu, T.S., Soules, M.E., Talsma, C.E., Gul, N., Koh, C., Zhang, J., Li, Y.M., Maciaczyk, J., et al. (2010). NOTCH pathway blockade depletes CD133-positive glioblastoma cells and inhibits growth of tumor neurospheres and xenografts. Stem Cells 28, 5-16.

Ferrara, N. (2004). Vascular endothelial growth factor: basic science and clinical progress. Endocr Rev 25, 581-611.

Gal, J.S., Morozov, Y.M., Ayoub, A.E., Chatterjee, M., Rakic, P., and Haydar, T.F. (2006). Molecular and morphological heterogeneity of neural precursors in the mouse neocortical proliferative zones. J Neurosci 26, 1045-1056.

Ghannad, M. (2011). The essential role of NDE1 in extreme microcephaly. Clin Genet 80, 241-242.

Glass, R., Synowitz, M., Kronenberg, G., Walzlein, J.H., Markovic, D.S., Wang, L.P., Gast, D., Kiwit, J., Kempermann, G., and Kettenmann, H. (2005). Glioblastoma-induced attraction of endogenous neural precursor cells is associated with improved survival. $\mathrm{J}$ Neurosci 25, 2637-2646.

Gordon, W.R., Arnett, K.L., and Blacklow, S.C. (2008). The molecular logic of Notch signaling - a structural and biochemical perspective. J Cell Sci 121, 3109-3119.

Gray, G.E., and Sanes, J.R. (1992). Lineage of radial glia in the chicken optic tectum. Development 114, 271-283.

Griffero, F., Daga, A., Marubbi, D., Capra, M.C., Melotti, A., Pattarozzi, A., Gatti, M., Bajetto, A., Porcile, C., Barbieri, F., et al. (2009). Different response of human glioma tumor-initiating cells to epidermal growth factor receptor kinase inhibitors. J Biol Chem 284, 7138-7148.

Halliday, A.L., and Cepko, C.L. (1992). Generation and migration of cells in the developing striatum. Neuron 9, 15-26.

Haubensak, W., Attardo, A., Denk, W., and Huttner, W.B. (2004). Neurons arise in the basal neuroepithelium of the early mammalian telencephalon: a major site of neurogenesis. Proc Natl Acad Sci U S A 101, 3196-3201.

Hegi, M.E., Diserens, A.C., Gorlia, T., Hamou, M.F., de Tribolet, N.,
Weller, M., Kros, J.M., Hainfellner, J.A., Mason, W., Mariani, L., et al. (2005). MGMT gene silencing and benefit from temozolomide in glioblastoma. N Engl J Med 352, 997-1003.

Higgins, J., Midgley, C., Bergh, A.M., Bell, S.M., Askham, J.M., Roberts, E., Binns, R.K., Sharif, S.M., Bennett, C., Glover, D.M., et al. (2010). Human ASPM participates in spindle organisation, spindle orientation and cytokinesis. BMC Cell Biol 11, 85.

Holmberg, J., He, X., Peredo, I., Orrego, A., Hesselager, G., Ericsson, C., Hovatta, O., Oba-Shinjo, S.M., Marie, S.K., Nistér, M., et al. (2011). Activation of neural and pluripotent stem cell signatures correlates with increased malignancy in human glioma. PLoS One 6, e18454.

Hopewell, J.W. (1975). The subependymal plate and the genesis of gliomas. J Pathol 117, 101-103.

Ignatova, T.N., Kukekov, V.G., Laywell, E.D., Suslov, O.N., Vrionis, F.D., and Steindler, D.A. (2002). Human cortical glial tumors contain neural stem-like cells expressing astroglial and neuronal markers in vitro. Glia 39, 193-206.

Jackson, A.P., Eastwood, H., Bell, S.M., Adu, J., Toomes, C., Carr, I.M., Roberts, E., Hampshire, D.J., Crow, Y.J., Mighell, A.J., et al. (2002). Identification of microcephalin, a protein implicated in determining the size of the human brain. Am J Hum Genet 71, 136-142.

Jackson, A.P., McHale, D.P., Campbell, D.A., Jafri, H., Rashid, Y., Mannan, J., Karbani, G., Corry, P., Levene, M.I., Mueller, R.F., et al. (1998). Primary autosomal recessive microcephaly (MCPH1) maps to chromosome 8p22-pter. Am J Hum Genet 63, 541-546.

Kaindl, A.M., Passemard, S., Kumar, P., Kraemer, N., Issa, L., Zwirner, A., Gerard, B., Verloes, A., Mani, S., and Gressens, P. (2010). Many roads lead to primary autosomal recessive microcephaly. Prog Neurobiol 90, 363-383.

Kornblum, H.I., Hussain, R., Wiesen, J., Miettinen, P., Zurcher, S.D., Chow, K., Derynck, R., and Werb, Z. (1998). Abnormal astrocyte development and neuronal death in mice lacking the epidermal growth factor receptor. J Neurosci Res 53, 697-717.

Kouprina, N., Pavlicek, A., Collins, N.K., Nakano, M., Noskov, V.N., Ohzeki, J., Mochida, G.H., Risinger, J.I., Goldsmith, P., Gunsior, M., et al. (2005). The microcephaly ASPM gene is expressed in proliferating tissues and encodes for a mitotic spindle protein. Hum Mol Genet 14, 2155-2165.

Kovall, R.A. (2008). More complicated than it looks: assembly of Notch pathway transcription complexes. Oncogene 27, 5099-5109.

Kriegstein, A., Noctor, S., and Martínez-Cerdeño, V. (2006). Patterns of neural stem and progenitor cell division may underlie evolutionary cortical expansion. Nat Rev Neurosci 7, 883-890.

Kriegstein, A.R., and Götz, M. (2003). Radial glia diversity: a matter of cell fate. Glia 43, 37-43.

Kumar, A., Girimaji, S.C., Duvvari, M.R., and Blanton, S.H. (2009). Mutations in STIL, encoding a pericentriolar and centrosomal protein, cause primary microcephaly. Am J Hum Genet 84, 286-290.

Lendahl, U., Zimmerman, L.B., and McKay, R.D. (1990). CNS stem cells express a new class of intermediate filament protein. Cell 60, 585-595.

Levitt, P., and Rakic, P. (1980). Immunoperoxidase localization of glial fibrillary acidic protein in radial glial cells and astrocytes of the developing rhesus monkey brain. J Comp Neurol 193, 815-840. 
Lin, J., Zhang, X.M., Yang, J.C., Ye, Y.B., and Luo, S.Q. (2010). g-secretase inhibitor-I enhances radiosensitivity of glioblastoma cell lines by depleting CD133+ tumor cells. Arch Med Res 41, 519-529.

Liu, G., Yuan, X., Zeng, Z., Tunici, P., Ng, H., Abdulkadir, I.R., Lu, L., Irvin, D., Black, K.L., and Yu, J.S. (2006). Analysis of gene expression and chemoresistance of CD133+ cancer stem cells in glioblastoma. Mol Cancer 5, 67.

LoTurco, J.J., Blanton, M.G., and Kriegstein, A.R. (1991). Initial expression and endogenous activation of NMDA channels in early neocortical development. J Neurosci 11, 792-799.

Luskin, M.B., Parnavelas, J.G., and Barfield, J.A. (1993). Neurons, astrocytes, and oligodendrocytes of the rat cerebral cortex originate from separate progenitor cells: an ultrastructural analysis of clonally related cells. J Neurosci 13, 1730-1750.

Maher, E.A., Furnari, F.B., Bachoo, R.M., Rowitch, D.H., Louis, D.N., Cavenee, W.K., and DePinho, R.A. (2001). Malignant glioma: genetics and biology of a grave matter. Genes Dev 15, 1311-1333.

Malatesta, P., Hartfuss, E., and Götz, M. (2000). Isolation of radial glial cells by fluorescent-activated cell sorting reveals a neuronal lineage. Development 127, 5253-5263.

Mapara, K.Y., Stevenson, C.B., Thompson, R.C., and Ehtesham, M. (2007). Stem cells as vehicles for the treatment of brain cancer. [ix.] Neurosurg Clin N Am 18, 71-80, ix.

Martínez-Cerdeño, V., Noctor, S.C., and Kriegstein, A.R. (2006). The role of intermediate progenitor cells in the evolutionary expansion of the cerebral cortex. Cereb Cortex 16, i152-i161.

Masui, K., Suzuki, S.O., Torisu, R., Goldman, J.E., Canoll, P., and Iwaki, T. (2010). Glial progenitors in the brainstem give rise to malignant gliomas by platelet-derived growth factor stimulation. Glia 58, 1050-1065.

Megraw, T.L., Sharkey, J.T., and Nowakowski, R.S. (2011). Cdk5rap2 exposes the centrosomal root of microcephaly syndromes. Trends Cell Biol 21, 470-480.

Miele, L., Miao, H., and Nickoloff, B.J. (2006). NOTCH signaling as a novel cancer therapeutic target. Curr Cancer Drug Targets 6, 313-323.

Mione, M.C., Danevic, C., Boardman, P., Harris, B., and Parnavelas, J.G. (1994). Lineage analysis reveals neurotransmitter (GABA or glutamate) but not calcium-binding protein homogeneity in clonally related cortical neurons. J Neurosci 14, 107-123.

Miyata, T., Kawaguchi, A., Okano, H., and Ogawa, M. (2001). Asymmetric inheritance of radial glial fibers by cortical neurons. Neuron 31, 727-741.

Miyata, T., Kawaguchi, A., Saito, K., Kawano, M., Muto, T., and Ogawa, M. (2004). Asymmetric production of surface-dividing and non-surface-dividing cortical progenitor cells. Development 131, 3133-3145.

Mizukami, Y., Kohgo, Y., and Chung, D.C. (2007). Hypoxia inducible factor-1 independent pathways in tumor angiogenesis. Clin Cancer Res 13, 5670-5674.

Mizutani, K., Yoon, K., Dang, L., Tokunaga, A., and Gaiano, N. (2007). Differential Notch signalling distinguishes neural stem cells from intermediate progenitors. Nature 449, 351-355.

Niethammer, M., Smith, D.S., Ayala, R., Peng, J.M., Ko, J., Lee, M.S. Morabito, M., and Tsai, L.H. (2000). NUDEL is a novel Cdk5 substrate that associates with LIS1 and cytoplasmic dynein. Neuron
28, 697-711

Nieto, M., Monuki, E.S., Tang, H., Imitola, J., Haubst, N., Khoury, S.J., Cunningham, J., Gotz, M., and Walsh, C.A. (2004). Expression of Cux-1 and Cux-2 in the subventricular zone and upper layers II-IV of the cerebral cortex. J Comp Neurol 479, 168-180.

Nishide, K., Nakatani, Y., Kiyonari, H., and Kondo, T. (2009). Glioblastoma formation from cell population depleted of Prominin1-expressing cells. PLoS One 4, e6869.

Niu, C.S., Li, D.X., Liu, Y.H., Fu, X.M., Tang, S.F., and Li, J. (2011). Expression of NANOG in human gliomas and its relationship with undifferentiated glioma cells. Oncol Rep 26, 593-601.

Noctor, S.C., Flint, A.C., Weissman, T.A., Dammerman, R.S., and Kriegstein, A.R. (2001). Neurons derived from radial glial cells establish radial units in neocortex. Nature 409, 714-720.

Noctor, S.C., Flint, A.C., Weissman, T.A., Wong, W.S., Clinton, B.K., and Kriegstein, A.R. (2002). Dividing precursor cells of the embryonic cortical ventricular zone have morphological and molecular characteristics of radial glia. J Neurosci 22, 3161-3173.

Noctor, S.C., Martínez-Cerdeño, V., Ivic, L., and Kriegstein, A.R. (2004). Cortical neurons arise in symmetric and asymmetric division zones and migrate through specific phases. Nat Neurosci 7 , 136-144.

Noctor, S.C., Martínez-Cerdeño, V., and Kriegstein, A.R. (2007a). Contribution of intermediate progenitor cells to cortical histogenesis. Arch Neurol 64, 639-642.

Noctor, S.C., Martinez-Cerdeno, V., and Kriegstein, A.R. (2007b). Neural stem and progenitor cells in cortical development. Novartis Found Symp 288, 59-73; discussion 73-58, 96-58.

Noguera-Troise, I., Daly, C., Papadopoulos, N.J., Coetzee, S., Boland, P., Gale, N.W., Lin, H.C., Yancopoulos, G.D., and Thurston, G. (2006). Blockade of Dll4 inhibits tumour growth by promoting non-productive angiogenesis. Nature 444, 1032-1037.

Pattison, L., Crow, Y.J., Deeble, V.J., Jackson, A.P., Jafri, H., Rashid, Y., Roberts, E., and Woods, C.G. (2000). A fifth locus for primary autosomal recessive microcephaly maps to chromosome $1 \mathrm{q} 31$. Am J Hum Genet 67, 1578-1580.

Plate, K.H., Breier, G., Weich, H.A., and Risau, W. (1992). Vascular endothelial growth factor is a potential tumour angiogenesis factor in human gliomas in vivo. Nature $359,845-848$.

Price, J., and Thurlow, L. (1988). Cell lineage in the rat cerebral cortex: a study using retroviral-mediated gene transfer. Development 104, 473-482.

Purow, B.W., Haque, R.M., Noel, M.W., Su, Q., Burdick, M.J., Lee, J., Sundaresan, T., Pastorino, S., Park, J.K., Mikolaenko, I., et al. (2005). Expression of Notch-1 and its ligands, Delta-like-1 and Jagged-1, is critical for glioma cell survival and proliferation. Cancer Res 65, 2353-2363.

Rakic, P. (1978). Neuronal migration and contact guidance in the primate telencephalon. Postgrad Med J 54, 25-40.

Reardon, D.A., Egorin, M.J., Desjardins, A., Vredenburgh, J.J., Beumer, J.H., Lagattuta, T.F., Gururangan, S., Herndon, J.E. 2nd, Salvado, A.J., and Friedman, H.S. (2009). Phase I pharmacokinetic study of the vascular endothelial growth factor receptor tyrosine kinase inhibitor vatalanib (PTK787) plus imatinib and hydroxyurea for malignant glioma. Cancer 115, 2188-2198.

Reynolds, B.A., Tetzlaff, W., and Weiss, S. (1992). A multipotent EGF-responsive striatal embryonic progenitor cell produces neurons and astrocytes. J Neurosci 12, 4565-4574. 
Ridgway, J., Zhang, G., Wu, Y., Stawicki, S., Liang, W.C., Chanthery, Y., Kowalski, J., Watts, R.J., Callahan, C., Kasman, I., et al. (2006). Inhibition of DIl4 signalling inhibits tumour growth by deregulating angiogenesis. Nature 444, 1083-1087.

Seidman, K.J., Teng, A.L., Rosenkopf, R., Spilotro, P., and Weyhenmeyer, J.A. (1997). Isolation, cloning and characterization of a putative type-1 astrocyte cell line. Brain Res 753, 18-26.

Shats, I., Gatza, M.L., Chang, J.T., Mori, S., Wang, J., Rich, J., and Nevins, J.R. (2011). Using a stem cell-based signature to guide therapeutic selection in cancer. Cancer Res 71, 1772-1780.

Siebzehnrubl, F.A., Jeske, I., Müller, D., Buslei, R., Coras, R., Hahnen, E., Huttner, H.B., Corbeil, D., Kaesbauer, J., Appl, T., et al. (2009). Spontaneous in vitro transformation of adult neural precursors into stem-like cancer cells. Brain Pathol 19, 399-408.

Singh, S.K., Clarke, I.D., Terasaki, M., Bonn, V.E., Hawkins, C., Squire, J., and Dirks, P.B. (2003). Identification of a cancer stem cell in human brain tumors. Cancer Res 63, 5821-5828.

Singh, S.K., Hawkins, C., Clarke, I.D., Squire, J.A., Bayani, J., Hide, T., Henkelman, R.M., Cusimano, M.D., and Dirks, P.B. (2004). Identification of human brain tumour initiating cells. Nature 432, 396-401.

Smart, I.H., Dehay, C., Giroud, P., Berland, M., and Kennedy, H. (2002). Unique morphological features of the proliferative zones and postmitotic compartments of the neural epithelium giving rise to striate and extrastriate cortex in the monkey. Cereb Cortex 12, 37-53.

Soeda, A., Inagaki, A., Oka, N., Ikegame, Y., Aoki, H., Yoshimura, S., Nakashima, S., Kunisada, T., and Iwama, T. (2008). Epidermal growth factor plays a crucial role in mitogenic regulation of human brain tumor stem cells. J Biol Chem 283, 10958-10966.

Sutton, L.N., Phillips, P., and Lange, B. (1992). Midline supratentorial tumors. Neurosurg Clin N Am 3, 821-837.

Tamamaki, N., Nakamura, K., Okamoto, K., and Kaneko, T. (2001). Radial glia is a progenitor of neocortical neurons in the developing cerebral cortex. Neurosci Res 41, 51-60.

Tamura, K., Aoyagi, M., Wakimoto, H., Ando, N., Nariai, T., Yamamoto, M., and Ohno, K. (2010). Accumulation of CD133-positive glioma cells after high-dose irradiation by Gamma Knife surgery plus external beam radiation. J Neurosurg 113, 310-318.

Tarabykin, V., Stoykova, A., Usman, N., and Gruss, P. (2001). Cortical upper layer neurons derive from the subventricular zone as indicated by Svet1 gene expression. Development 128, 1983-1993.

Tischfield, M.A., Cederquist, G.Y., Gupta, M.L. Jr, and Engle, E.C. (2011). Phenotypic spectrum of the tubulin-related disorders and functional implications of disease-causing mutations. Curr Opin Genet Dev 21, 286-294.

Tohyama, T., Lee, V.M., Rorke, L.B., Marvin, M., McKay, R.D., and Trojanowski, J.Q. (1992). Nestin expression in embryonic human neuroepithelium and in human neuroepithelial tumor cells. Lab Invest 66, 303-313.

Uhrbom, L., Dai, C., Celestino, J.C., Rosenblum, M.K., Fuller, G.N., and Holland, E.C. (2002). Ink4a-Arf loss cooperates with KRas activation in astrocytes and neural progenitors to generate glioblastomas of various morphologies depending on activated Akt. Cancer Res 62, 5551-5558.

Uhrbom, L., Hesselager, G., Nistér, M., and Westermark, B. (1998). Induction of brain tumors in mice using a recombinant platelet-derived growth factor B-chain retrovirus. Cancer Res 58 , 5275-5279.

Umeshima, H., Hirano, T., and Kengaku, M. (2007). Microtubulebased nuclear movement occurs independently of centrosome positioning in migrating neurons. Proc Natl Acad Sci U S A 104, 16182-16187.

Vick, N.A., Lin, M.J., and Bigner, D.D. (1977). The role of the subependymal plate in glial tumorigenesis. Acta Neuropathol 40, 63-71.

Wechsler-Reya, R., and Scott, M.P. (2001). The developmental biology of brain tumors. Annu Rev Neurosci 24, 385-428.

Weissman, T.A., Riquelme, P.A., Ivic, L., Flint, A.C., and Kriegstein, A.R. (2004). Calcium waves propagate through radial glial cells and modulate proliferation in the developing neocortex. Neuron 43, $647-661$.

Wells, A., Kassis, J., Solava, J., Turner, T., and Lauffenburger, D.A. (2002). Growth factor-induced cell motility in tumor invasion. Acta Oncol 41, 124-130.

Wu, D.K., and Cepko, C.L. (1993). Development of dopaminergic neurons is insensitive to optic nerve section in the neonatal rat retina. Brain Res Dev Brain Res 74, 253-260.

Yoon, K.J., Koo, B.K., Im, S.K., Jeong, H.W., Ghim, J., Kwon, M.C., Moon, J.S., Miyata, T., and Kong, Y.Y. (2008). Mind bomb 1-expressing intermediate progenitors generate notch signaling to maintain radial glial cells. Neuron $58,519-531$.

Yuan, X., Curtin, J., Xiong, Y., Liu, G., Waschsmann-Hogiu, S., Farkas, D.L., Black, K.L., and Yu, J.S. (2004). Isolation of cancer stem cells from adult glioblastoma multiforme. Oncogene 23, 9392-9400.

Zbinden, M., Duquet, A., Lorente-Trigos, A., Ngwabyt, S.N., Borges, I., and Ruiz i Altaba, A. (2010). NANOG regulates glioma stem cells and is essential in vivo acting in a cross-functional network with GLI1 and p53. EMBO J 29, 2659-2674.

Zhang, M., Song, T., Yang, L., Chen, R., Wu, L., Yang, Z., and Fang, J. (2008). Nestin and CD133: valuable stem cell-specific markers for determining clinical outcome of glioma patients. J Exp Clin Cancer Res 27, 85.

Zhu, H., Acquaviva, J., Ramachandran, P., Boskovitz, A., Woolfenden, S., Pfannl, R., Bronson, R.T., Chen, J.W., Weissleder, R., Housman, D.E., et al. (2009). Oncogenic EGFR signaling cooperates with loss of tumor suppressor gene functions in gliomagenesis. Proc Natl Acad Sci U S A 106, 2712-2716.

Zimmer, C., Tiveron, M.C., Bodmer, R., and Cremer, H. (2004). Dynamics of Cux2 expression suggests that an early pool of SVZ precursors is fated to become upper cortical layer neurons. Cereb Cortex 14, 1408-1420. 